\title{
OPEN Omics approaches for conservation biology research on the bivalve Chamelea gallina
}

\begin{abstract}
Federica Carducci ${ }^{1,2}$, Maria Assunta Biscotti ${ }^{1,2}$, Emiliano Trucchi ${ }^{1}$, Maria Elisa Giuliani ${ }^{1}$, Stefania Gorbi ${ }^{1}$, Alessandro Coluccelli ${ }^{1}$, Marco Barucca ${ }^{1,2}$ \& Adriana Canapa ${ }^{1,2}$

The striped venus (Chamelea gallina) is an important economic resource in the Mediterranean Basin; this species has exhibited a strong quantitative decline in the Adriatic Sea. The aim of this work was to provide a comprehensive view of the biological status of $C$. gallina to elucidate the bioecological characteristics and genetic diversity of wild populations. To the best of our knowledge, this investigation is the first to perform a multidisciplinary study on C. gallina based on two omics approaches integrated with histological, ecotoxicological, and chemical analyses and with the assessment of environmental parameters. The results obtained through RNA sequencing indicated that the striped venus has a notable ability to adapt to different environmental conditions. Moreover, the stock reduction exhibited by this species in the last 2 decades seems not to have negatively affected its genetic diversity. Indeed, the high level of genetic diversity that emerged from our ddRAD dataset analyses is ascribable to the high larval dispersal rate, which might have played a "compensatory role" on local fluctuations, conferring to this species a good adaptive potential to face the environmental perturbations. These findings may facilitate the efforts of conservation biologists to adopt ad hoc management plans for this fishery resource.
\end{abstract}

Commercially important marine species are frequently threatened by the effects of environmental changes, pollution, microbiological diseases, and overfishing, which may cause reductions in the size and genetic diversity of wild populations.

The development of omics sciences provides a remarkable contribution to species conservation biology, significantly increasing the ability of researchers to obtain insights into the molecular mechanisms adopted by species to cope environmental change ${ }^{1}$. The integration of data obtained from different omics approaches with ecotoxicological and environmental assessments has the advantage of creating a more holistic understanding of species, enabling researchers to develop specific tools to implement long-term management plans ${ }^{2}$.

Chamelea gallina (Linnaeus, 1758) is a mollusk species that is of considerable importance, both economically and ecologically. This bivalve, which belongs to the Veneridae family, is widely distributed along the eastern Atlantic coast, ranging from, Norway and the British Isles to the Iberian Peninsula, Morocco, the Madeira Islands and the Canary Islands ${ }^{3}$. This species is also observed in the Black Sea, Mediterranean waters ${ }^{4}$ and particular in the Adriatic Sea ${ }^{5}$. C. gallina is a gonochoristic species with a long spawning period, extending from April to August, in which egg emission takes place at intervals ${ }^{6-12}$. In the Adriatic Sea, the fishery of C. gallina represents one of the most important resources with approximately 15,000 $t$ reported for the year $2018^{13}$, involving 670 fisheries with an annual turnover of approximately 100 million euros. For the Black Sea, the highest yield is reported in Turkey with approximately $40,000 \mathrm{t}$ of annual catches ${ }^{10}$. C. gallina, similar to other marine bivalves, is also important in ecosystems, impacting nutrient cycling, creating and modifying habitats, and affecting food webs directly (i.e., prey) and indirectly (i.e., movement of nutrients and energy) ${ }^{14}$. Moreover, due to their filter-feeding abilities and their sessile mode of life, these bivalves play important roles as biosensors for pollution and other environmental changes in coastal waters, enabling the monitoring of the quality of the intertidal zones $^{15-18}$. Several factors, including temperature variation, salinity, dissolved oxygen concentration in water and sediment ${ }^{19-23}$, presence of toxic substances of anthropogenic origin ${ }^{24}$, and overfishing ${ }^{25}$, might have induced a decrease in this fishery resource ${ }^{12}$.

\footnotetext{
${ }^{1}$ Dipartimento di Scienze della Vita e dell'Ambiente, Università Politecnica delle Marche, Ancona, Italy. ${ }^{2}$ These authors contributed equally: Federica Carducci, Maria Assunta Biscotti, Marco Barucca and Adriana Canapa. ${ }^{\circledR}$ email: a. canapa@univpm.it
} 
In the Adriatic Sea, several mortality events due to sudden changes in the coastal environment (anoxia, river runoff, storm surges, pollution, and bacterial and/or viral infections) have strongly contributed to the decline of clam beds ${ }^{12,26,27}$ from approximately 35,000-15,000 $t$ in the last 2 decades (FAO FishStat).

To date, the molecular resources available for C. gallina are the transcriptome published by Coppe et al. ${ }^{28}$ and gene expression analyses obtained by Milan and colleagues ${ }^{26,27}$, which detected differences between organisms sampled from two close sites with different local periodic mortality rates in the Italian Adriatic region of Abruzzo. Moreover, very little is known regarding the genetic substructure of C. gallina ${ }^{29}$.

Therefore, to ensure the long-term sustainability of fishery resources, further research elucidating the bioecological properties and the genetic diversity of wild C. gallina populations is required.

The utilization of high-throughput sequencing techniques, such as RNA sequencing (RNA-Seq) and double digest restriction-site associated DNA sequencing (ddRAD-Seq), is acquiring increasing recognition in the conservation biology research on sensitive and economically important species ${ }^{30-32}$. In particular, RNA-Seq is the favored sequencing technique to obtain knowledge on the functional response of organisms to environmental conditions. Indeed, in a multistress context, this technique enables us to depict the alteration of several genes and molecular pathways simultaneously in nonmodel organisms in response to stressful conditions ${ }^{33-35}$. ddRAD sequencing is one of the most powerful approaches to resolve fine-scale population structures compared with microsatellites, since ddRAD enables researchers to obtain thousands of markers ${ }^{36,37}$. This approach enables us to obtain a comprehensive view of genetic variability that represents a measure of the ability of species to adapt to environmental perturbations. Indeed, species showing low levels of genetic diversity are more prone to extinction. In line with these premises, this work attempted to provide, for the first time, a multidisciplinary strategy to elucidate the functional response of C. gallina to several biotic and abiotic factors and the genetic diversity level of the striped venus natural beds, as determined through RNA and ddRAD sequencing techniques. Moreover, to better contextualize the results obtained by combining omics approaches, we performed detailed histological, ecotoxicological, and chemical analyses and an assessment of environmental parameters.

\section{Results}

Transcriptomic analyses. RNA sequencing analyses were performed on individuals collected in spring and autumn 2018 from Senigallia (S) and Silvi Marina (SM), two sites to the north and south of Monte Conero, respectively, and belonging to two distinct biogeographic sectors. Differences in gene expression levels between the two sampling sites and sampling times were assessed by performing pairwise comparisons, as reported in Supplementary Fig. S1. The numbers of differentially expressed genes (DEGs) obtained using DESeq2 are shown in Supplementary Table S1. Principal component analyses (Supplementary Fig. S2) showed PC1 with a percentage of $\geq 69 \%$, supporting a clear difference between the two sampling sites (Supplementary Fig. S2A and B) and between the two sampling periods (Supplementary Fig. S2C and D). In addition, the low percentage of PC2 suggested a good degree of concordance of the three biological replicates in each pairwise comparison (Supplementary Fig. S2). DEGs were investigated to identify the most significant biological processes and pathways involved in the functional response of C. gallina to continuously changing environmental conditions. Up- and downregulated genes were functionally annotated through pathway enrichment analyses for all pairwise comparisons performed in this study (Supplementary Fig. S1). For the S sampling site, between spring and autumn, genes upregulated in spring fell within genetic information processing (41 genes), energy metabolism (29 genes), environmental information processing (21 genes), protein families: genetic information processing (21 genes), and carbohydrate metabolism (15 genes). For this sampling site, genes upregulated in autumn were more closely related to genetic information processing and protein families: genetic information processing (53 genes) (Fig. 1). For the SM sampling site, these latter enriched pathways were more strongly represented within the upregulated genes in spring, while in autumn, carbohydrate metabolism (26 genes), genetic information processing (18 genes), environmental information processing (17 genes), and protein families: genetic information processing (16 genes) were the most common. Furthermore, another comparison was performed between the two sampling sites in both sampling periods. Concerning the genes upregulated in spring for specimens sampled in S, genetic information processing (18 genes), energy metabolism (12 genes), environmental information processing (12 genes), and carbohydrate metabolism (11 genes) were the most heavily represented, while for the upregulated genes in the SM sampling site, genes fell primarily within genetic information processing (21 genes) and energy metabolism (3 genes). An opposite pattern was observed when analyzing the enriched pathways related to the comparison between S and SM in autumn (Fig. 1).

Focus on specific pathways. In analyzing data related to functional enrichment made using KEGG for the comparison between the two sampling sites and periods (Fig. 1), this research focused on genes involved in specific pathways.

Cellular processes. In KEGG pathway enrichment analysis, cellular processes included transport and catabolism, cell growth and death, cellular community (eukaryotes and prokaryotes), and cell motility.

Functional annotation of the upregulated genes in the autumn period for the sampling site of SM enabled us to retrieve 22 entries that fall in the section of cell growth and death. In particular, the presence of the SCF complex (Skp-Cullin, F-box containing complex), calmodulin, 14-3-3e protein, C-Myc binding protein, Dna J subfamily member 13, and spermatogenesis associated 4 among the upregulated gametogenesis-related genes was reported. At the same time, the absence of the SCF complex within the upregulated genes in functional enrichment analyses of the autumnal period at the $S$ site was strongly in keeping with histological analyses showing gonadal inactivity (Fig. 2). 
SM spring vs autumn
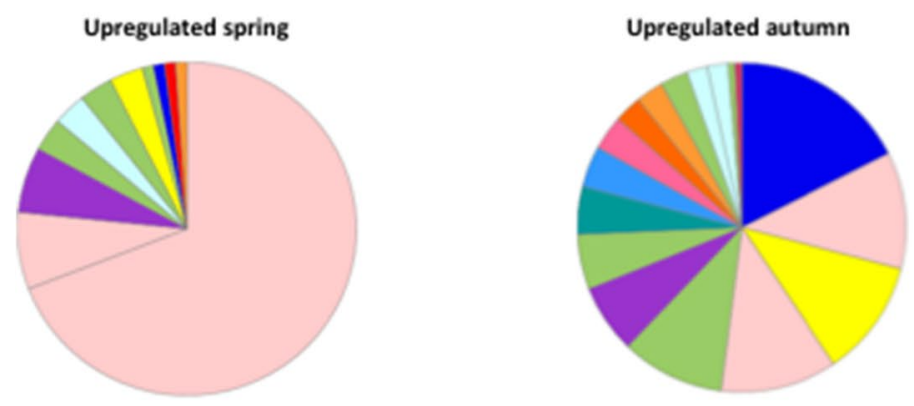

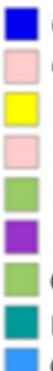

Carbohydrate metabolism Genetic information processing Environmental information processing Protein families: genetic information processing Protein families: signaling and cellular processes Energy metabolism Cellular processes Lipid metabolism

Glycan biosynthesis and metabolism

Metabolism of cofactors and vitamins Metabolism of other amino acids Protein families: metabolism

Nucleotide metabolism

Amino acids metabolism
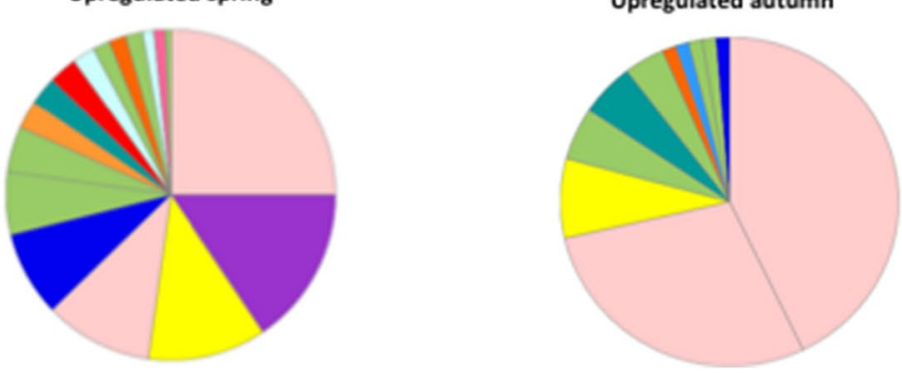

Figure 1. Graphical view of pathway enrichment analyses performed with KEGG BlastKOALA on transcriptomic data. Pathway enrichment analyses are shown ${ }^{93-95}$. In the upper side of the panel, comparisons between transcriptomic data obtained from clams collected at the two sampling times in SM. On the lower side of the panel, comparisons between transcriptomic data obtained from clams collected at the two sampling times in $S$.

Energy, lipid, and carbohydrate metabolism. Energy metabolism plays a key role in the onset of reproduction ${ }^{26,38}$; thus, its analysis in bivalves, primary consumers of the aquatic food chain ${ }^{39}$, might help to elucidate their reproductive stage.

The variable level of food availability that depends on abiotic factors, such as solar radiation, salinity, and sea surface temperature ${ }^{40}$, influences the opportunistic behavior of C. gallina ${ }^{38}$.

The results obtained from the DEG pathway enrichment analysis showed the presence within the upregulated genes of 33 genes related to energy metabolism, particularly of oxidative phosphorylation, together with the carbohydrate metabolism and lipid metabolism in the SM sampling site during the autumn period; these functional categories were less heavily represented in the upregulated genes of the spring period (Fig. 1). These pathways were closely connected with the employment of energetic resources in the production of ATP and ready-to-use energy for possible gamete production. Inverted and more pronounced, this trend of enriched pathways related to metabolism was observed in the comparison made for the DEGs of S specimens between the two sampling periods. In this case, the upregulated genes of the spring period were in energy metabolism (28 entries) and carbohydrate metabolism (15 entries), while in autumn, only 1 entry was in carbohydrate metabolism, and no entries were in energy metabolism. (Fig. 1). These findings may be explained by analyzing the data obtained in this study for the chlorophyll seasonal availability trend (Fig. 3), which suggests a higher food intake for S specimens collected in the spring period, which supports the activation of energy metabolism and earlier gametogenesis compared to SM specimens collected in the same period; this finding is in keeping with observations shown by the analysis of the cellular processes pathway.

Ecotoxicological and chemical analyses. Clams collected in spring displayed a higher Condition Index (CI) than those sampled in autumn when a decrease was observed at SM compared to S (Fig. 4A). The lysosomal membrane stability in clam hemocytes exhibited no significant variations depending on season and site, although slightly lower values were detected in autumn than in spring (Fig. 4B).

The activity of acetylcholinesterase (AChE), as measured with a hemocytes, showed a nonsignificant increase in autumn compared to spring at both sites (Fig. 4C).

A significant difference in metallothionein content in the digestive glands was observed in clams collected at SM in spring compared to the values detected in the other sampling groups (Fig. 4D).

Antioxidants, measured in the digestive glands, showed fluctuations primarily related to the season. A slight increase was observed for CAT activity in autumn compared to spring, independent of the sampling site (Fig. 4E). The clams sampled in S exhibited significantly lower activities of all glutathione-dependent enzymes (GST, GR, Se-GPx, and total GPx) in autumn compared to those reported for the spring period; the values of the same 

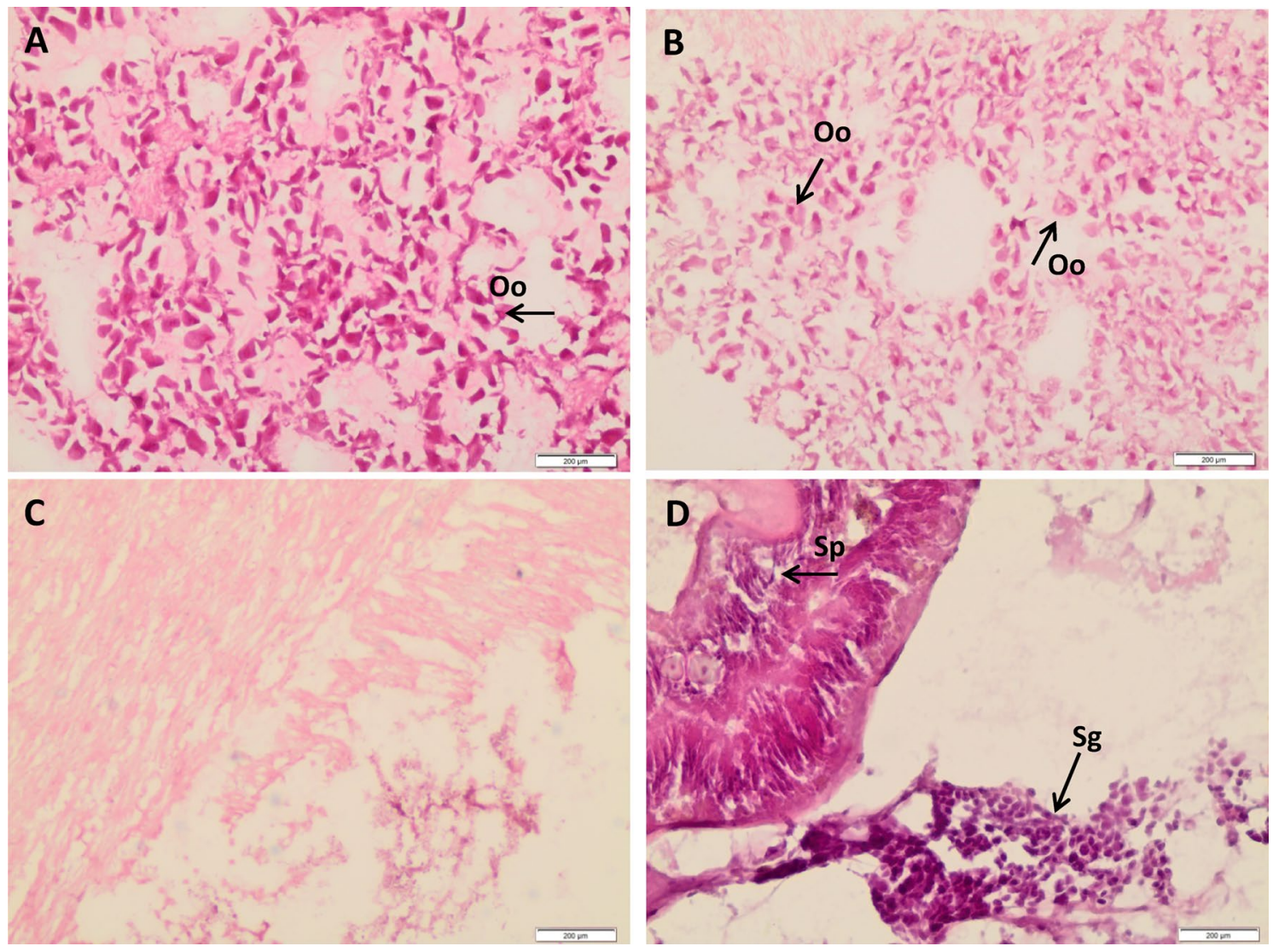

Figure 2. Histological analyses. Chamelea gallina gonadal sections made for the two sampling sites and periods: (A) S and (B) SM refer to the spring sampling period; (C) S and (D) SM refer to the autumn sampling period. Scale bars are $200 \mu \mathrm{m}$. Black arrows in (A) and (B) focus on oocytes (Oo) and their vitellogenic content. Black arrows in (D) focus on spermatozoa (Sp) and spermatogonia (Sg).
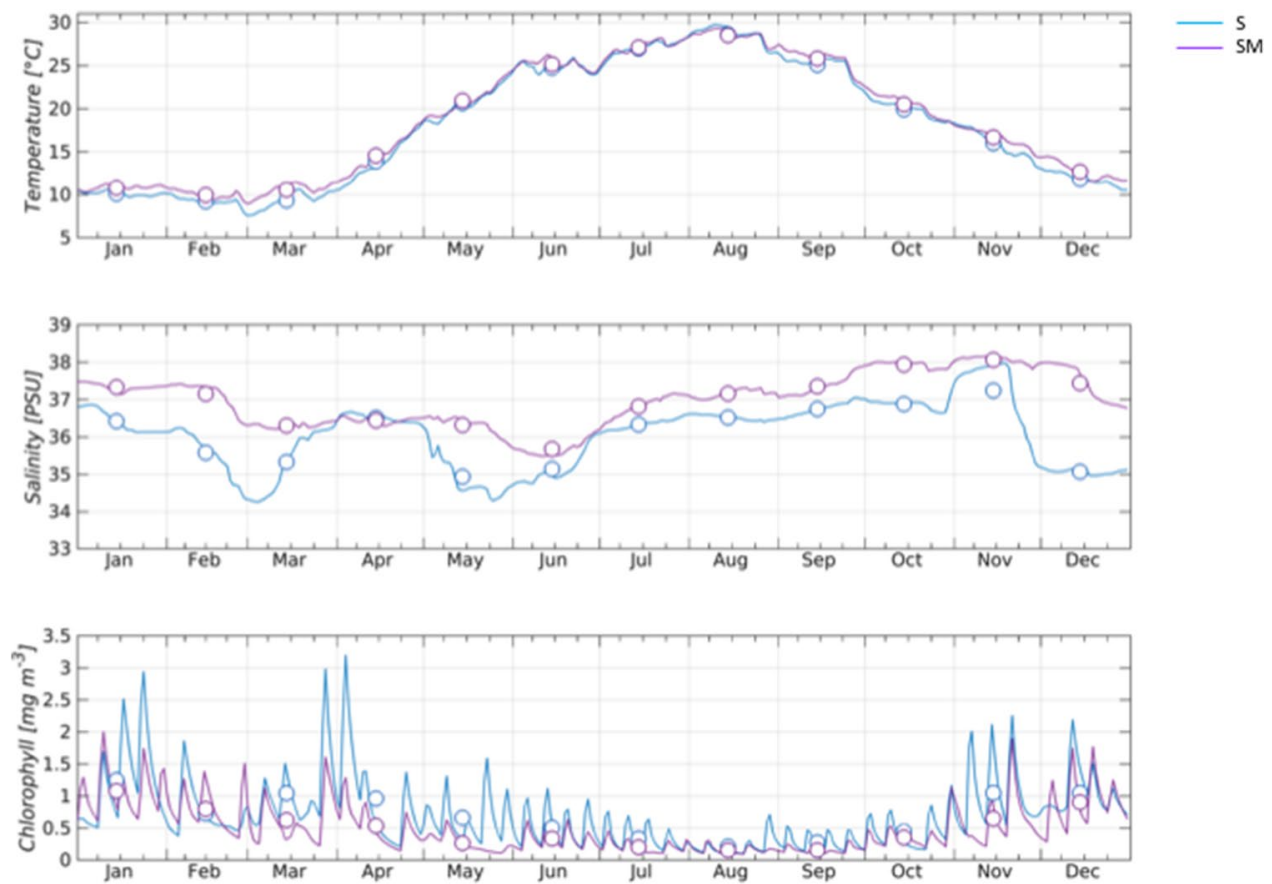

Figure 3. Time series of environmental parameters. Daily temperature (upper panel), salinity (middle) and chlorophyll (lower panel) at the sampling stations of S (blue line) and SM (purple line). Computed monthly means are superimposed as circles. 

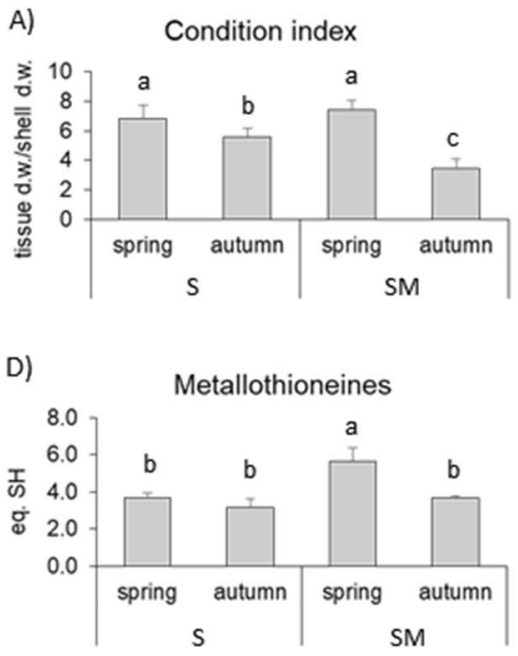

G)

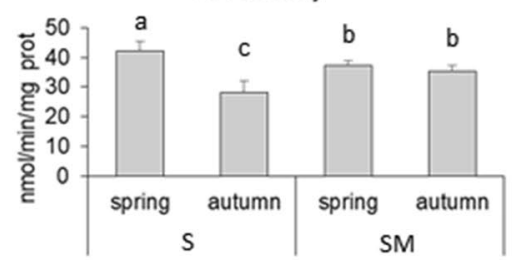

J)

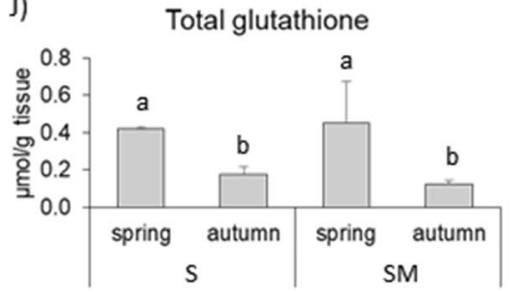

B)

Lysosomal membrane stability

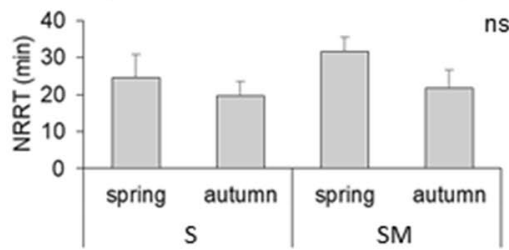

E)

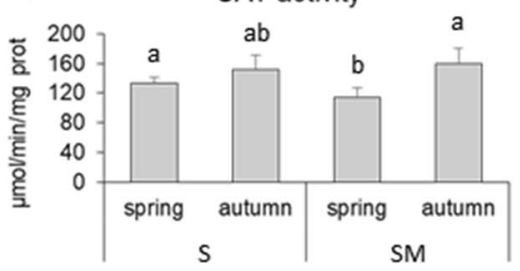

H)

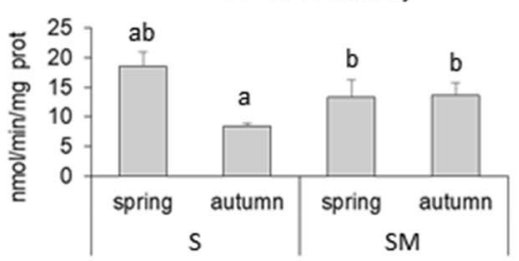

K)

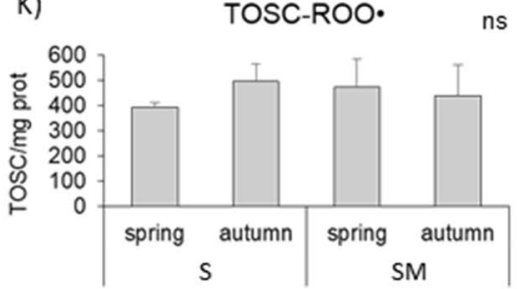

C)

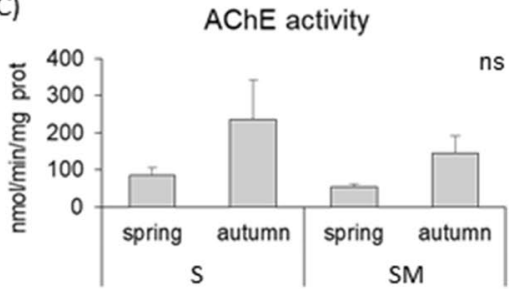

F)

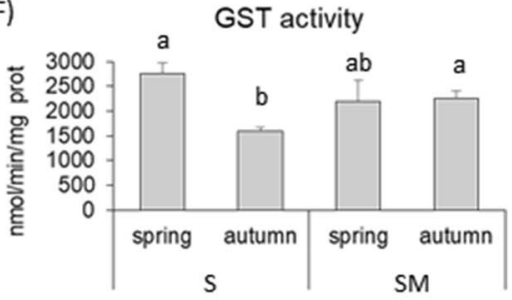

I)

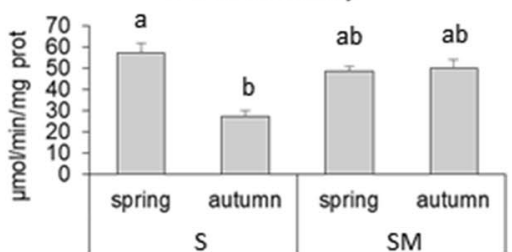

L)

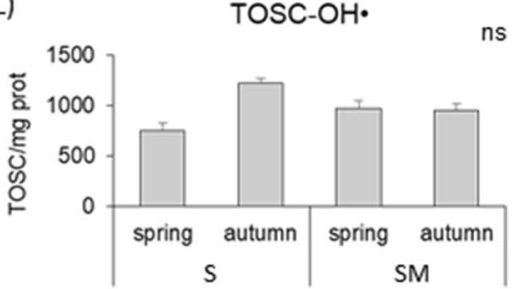

Figure 4. Biomarker responses analyzed in the clams Chamelea gallina collected in S and SM in spring and autumn 2018. (A) Condition Index of individuals $(n=30)$. (B) Lysosomal membrane stability in hemocytes $(n=5)$; NRRT $=$ neutral red retention time. $(C)$ Activity of acetylcholinesterase (AChE) in hemocytes $(n=5)$. (D-I) Activity of metallothioneines, catalase (CAT), glutathione S-transferases (GST), glutathione reductase (GR), Se-dependent glutathione peroxidases (Se-GPX) and total glutathione peroxidases (Tot-GPX) in the clam digestive gland $(n=5)$. (J) Total glutathione amount in digestive glands $(n=5)$. $(K-\mathbf{L})$ Total oxyradical scavenging capacity (TOSC) against peroxyl radicals (ROO.) and hydroxyl radicals ( $\mathrm{OH} \cdot$ ) measured in digestive glands $(n=5)$. All values are expressed as the mean \pm standard deviation.

enzymatic activities in clams from SM were constant during the two seasons, remaining at an intermediate level compared to those displayed in S clams (Fig. 4F-I). The amount of total glutathione was lower in autumn than in spring in clams from both sites (Fig. 4J). No significant differences were observed for the total oxyradical scavenging capacity (Fig. $4 \mathrm{~K}-\mathrm{L}$ ).

The bioaccumulation analyses in clam tissues revealed limited variations in the different analyzed parameters (metals and PAHs), with the measured levels being similar to those typically observed in organisms from reference areas (Supplementary Table S2).

Assessment of environmental parameters. Extracted timeseries span the year 2018. Data were provided as daily means for temperature, salinity, and chlorophyll (Fig. 3). Supplementary Tables S3 and S4 show the monthly and seasonal averages and the standard errors for the S and SM sampling sites, respectively. The results of the ANOVA and Tukey's test show that there were no significant differences ( $p$ value $>0.05)$ between the two sampling stations in terms of seasonal temperature (Supplementary Table S5), whereas significant differences observed ( $p$ value $<0.05$ ) for salinity in all seasons and for chlorophyll concentration in winter, spring and autumn. It can also be noted (Fig. 3) that salinity is generally lower at the S location due to the low salinity waters that are always present along the western coast, being related to river runoff ${ }^{41}$, particularly in the northern and middle part of the Adriatic Sea above the Monte Conero region. Analysis of the differences between the two stations on a monthly basis revealed that chlorophyll concentration is significantly different from March to May 
and in November when the S site was characterized by higher productivity (Fig. 3). The pairwise comparison among seasonal means of each parameter and at each sampling site (Supplementary Table S6) highlighted the expected differences in temperature and chlorophyll concentration, as these parameters have a clear seasonal pattern.

Population genetics. A total of 10,543 paired-end loci with a mean length of ca. $230 \mathrm{bp}$ and a total number of ca. 450,000 single nucleotide polymorphisms (SNPs) were de novo assembled and filtered by Stacks2.4 algorithms. Only ca. three hundred loci found a match in the GenBank nt database (1e-04), primarily with sequences identified as Bivalvia (Figure S3). After filtering out individuals with more than $50 \%$ missing loci and loci with more than 25\% missing individuals, our dataset included 2004 loci and 155 individuals, showing a mean coverage per locus of ca. $60 \mathrm{X}$, a mean number of ca. 50 SNPs and 65 alleles per locus. The distribution of alleles and SNPs per locus appeared largely unimodal (a minor drop of approximately 45-50 SNPs per locus was further investigated; see Supplementary Fig. S3A and B). The marked difference in the amount of missing data between Tyrrhenian and Adriatic individuals is likely due to differential allele drop-out between the two groups, as supported by the principal component analysis (PCA) ${ }^{42}$ inferred on loci presence/absence (Supplementary Fig. S3C and D). Consistent with this finding, we inferred two populations with fineRADstructure corresponding to the Tyrrhenian and the Adriatic Sea (Fig. 5 and Supplementary Fig. S3E-H). In addition to a few individuals (mainly from $S$ in the Adriatic Sea showing a higher coancestry with each other), the Adriatic population appeared to be fully panmictic, thereby suggesting a high level of gene flow among all sampled localities. The inferred genetic structure was robust to missing data (i.e., excluding individuals with more than $25 \%$ missing loci) and locus variability (i.e., including only loci with less than 45 SNPs). Most of the diversity within each population was attributable to low-frequency variants (Fig. 6); the average $\pi$ per locus was $2.5 \mathrm{e}-4$ and $2.3 \mathrm{e}-4$ in Tyrrhenian and Adriatic populations, respectively, and the $F_{S T}$ between the two populations was 0.075 . The demographic reconstruction of the Adriatic population shows no sign of recent decline, as it is instead evident in the Tyrrhenian population (Fig. 6). Even if it is not possible to define a timewise framework for these reconstructions due to the lack of a reliable estimate of the substitution rate in this species, the comparison between the two histories is noteworthy.

\section{Discussion}

The striped venus is an important economic resource in the Mediterranean Basin. However, it is known that in the Adriatic Sea, this species experienced a quantitative decline, and several factors have been suggested to be responsible for the reduction of natural clam beds.

In this study, for the first time, we employed two omics approaches based on high-throughput sequencing, the integration of which may be able to provide a comprehensive view of the biological status of the striped venus: RNA sequencing was performed to obtain information on the functional status of C. gallina in relation to several biotic and abiotic factors, and ddRAD sequencing was employed to assess if the genetic diversity level was enough to ensure the adaptive potential of the species to cope environmental perturbations to which it is continuously subjected. Moreover, ecotoxicological and chemical analyses, assessment of environmental parameters, and histological observations were performed to better contextualize the obtained data.

Transcriptomic analyses were performed on specimens collected in spring and autumn at two sampling sites located along the middle Adriatic coast of Italy. These two sites were chosen because of their economic importance in two maritime fishing districts. Moreover, the two sampling sites are located in the north and south of Monte Conero and belong to two different biogeographic sectors ${ }^{43}$. The promontory at this location influences water circulation patterns and the diffusion of runoff waters coming from the main northern Adriatic river (the Po River). The functional enrichment analyses on the DEGs obtained from the performed comparisons demonstrated a different representation of some pathways between specimens of the two sites and within the same site between specimens of the two sampling periods (Fig. 1).

Overall, most of the entries fall into the categories of genetic information processing and protein families: genetic information processing, whose genes are primarily related to the synthesis of ribosomal components. In particular, pathways referring to gametogenesis and reproduction, such as cellular processes and energy, lipids, and carbohydrate metabolism, are the most heavily represented in the spring sampling period of $S$ and in the autumn period of SM.

Of significant interest was the presence of the SCF complex in the enriched pathway of specimens collected in the sampling site of SM in the autumnal period and absent within upregulated genes in functional enrichment analyses of the autumnal period in S. This gene is involved in the degradation of the Emi1 and Emi2 (early mitotic inhibitor 1 and 2) proteins, which are necessary for the progression of meiosis I and II, respectively ${ }^{44}$. Another upregulated gene identified in the same pathway was calmodulin, a mediator of cell cycle progression from meiosis I to meiosis II. In addition, 14-3-3ع protein was found among the upregulated genes. This biomolecule belongs to a highly conserved protein family that is involved in a wide range of roles in cellular processes in all eukaryotes $^{45}$, including the control of the cell cycle and the regulation of apoptosis ${ }^{46}$. Interestingly, the schematic representation of the oocyte meiosis-enriched pathway shows the 14-3-3e isotype in its dissociated form, essential for the progression of meiosis I. Indeed, the 14-3-3e isotype binds the cell division cycle 25C (CDC25C) protein, thereby preventing cell cycle progression ${ }^{47}$.

Among the upregulated genes of sampling site $S$ in the spring period and in SM in the autumnal period, male-specific genes involved in bivalve species gametogenesis ${ }^{48}$, such as C-Myc binding protein, DnaJ subfamily member 13, and spermatogenesis associated 4, were observed. All these findings suggest a timeline discrepancy in gonadal development in SM specimens compared to those collected at the S sampling site. 


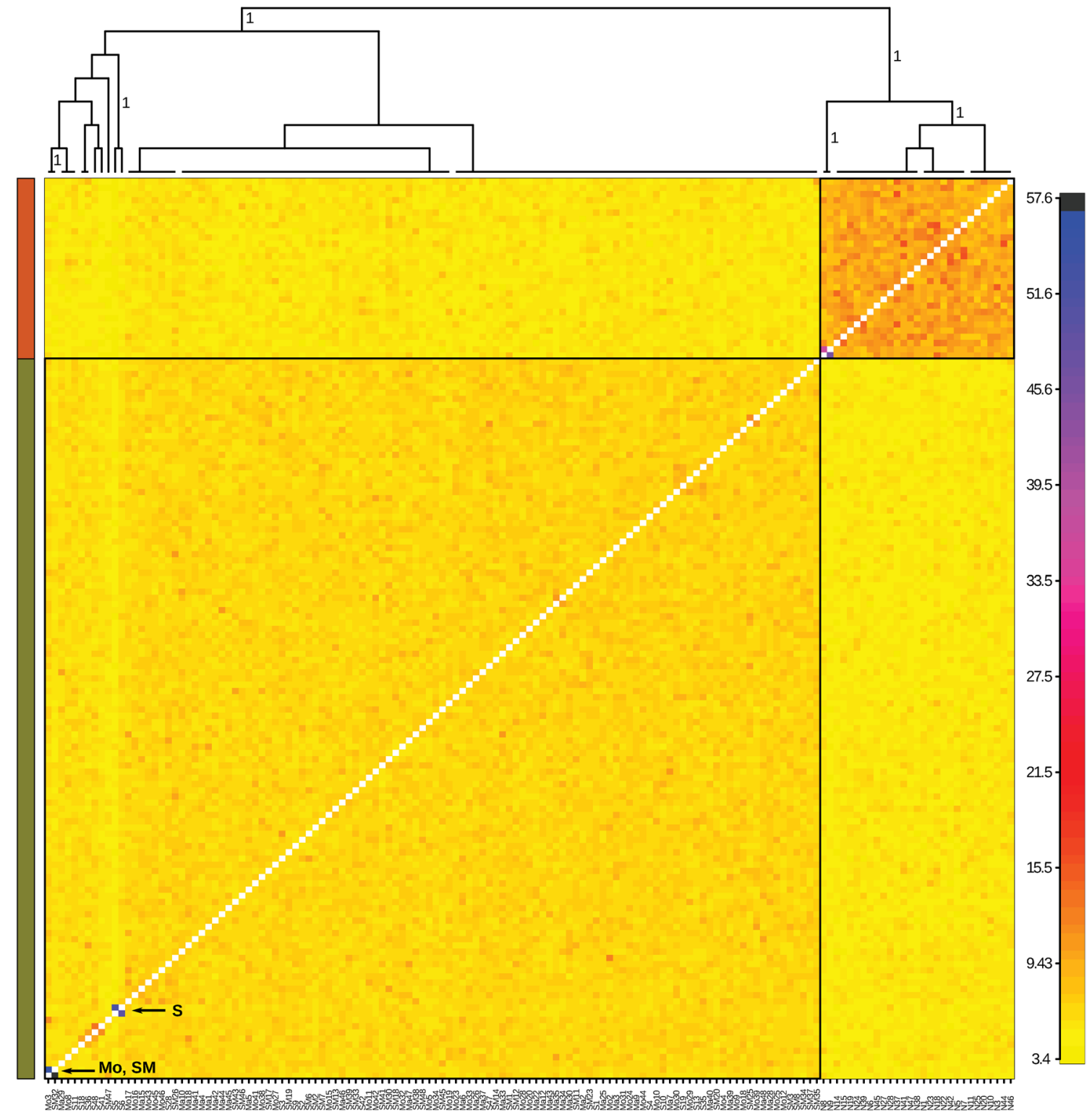

Figure 5. Structure of genomic diversity in striped venus from the Adriatic (green) and Tyrrhenian (orange) Seas. Coancestry matrix inferred by fineRADstructure using individuals with less than $25 \%$ missing data and loci with less than 45 SNPs (see also Figure S3b). The number of loci for which any two individuals are the closest relatives is coded according to the palette on the right. FineRADstructure Bayesian cladogram of the inferred ("natural" $k$ ) groups, with branch labels showing the posterior support for all of the included individuals to be assigned to that group, is shown at the top. The Adriatic population includes samples from Ma, Mo, S, and $\mathrm{SM}$, whereas only $\mathrm{N}$ is the locality from the Tyrrhenian Sea. Few more-related-than-average individuals are highlighted.

These observations were consistent with histological analyses, showing ongoing gametogenesis in SM specimens collected in the autumnal period in contrast to $S$ clams. This finding is also in line with values observed for the Condition Index, a general indicator of the physiological status of organisms. In our case, lower values were recorded for specimens collected in the sampling site of SM in autumn. Lucas and Beninger $(1985)^{49}$ have affirmed that a low value for this index may be the consequence of an intense biological effort that might be due to the gamete production process of the clams in this study.

Artigaud and colleagues in $2015^{50}$ reported an increase in the metabolic rate of animals, which was strictly related to glycolysis. In mollusks, an upregulation of the glycolytic pathway has been described during thermal acclimation in providing additional energy resources ${ }^{51,52}$. However, in our case study, the absence of substantial variations regarding surface water temperature enabled us to exclude the possibility that differences in metabolic rates observed between specimens of SM and S might be related to this type of environmental stressor. Therefore, variations in metabolic rates for C. gallina might be linked to the values observed for phytoplankton availability and, consequently, to food intake that could, in turn, have influenced the reproductive state in an opportunistic species. 


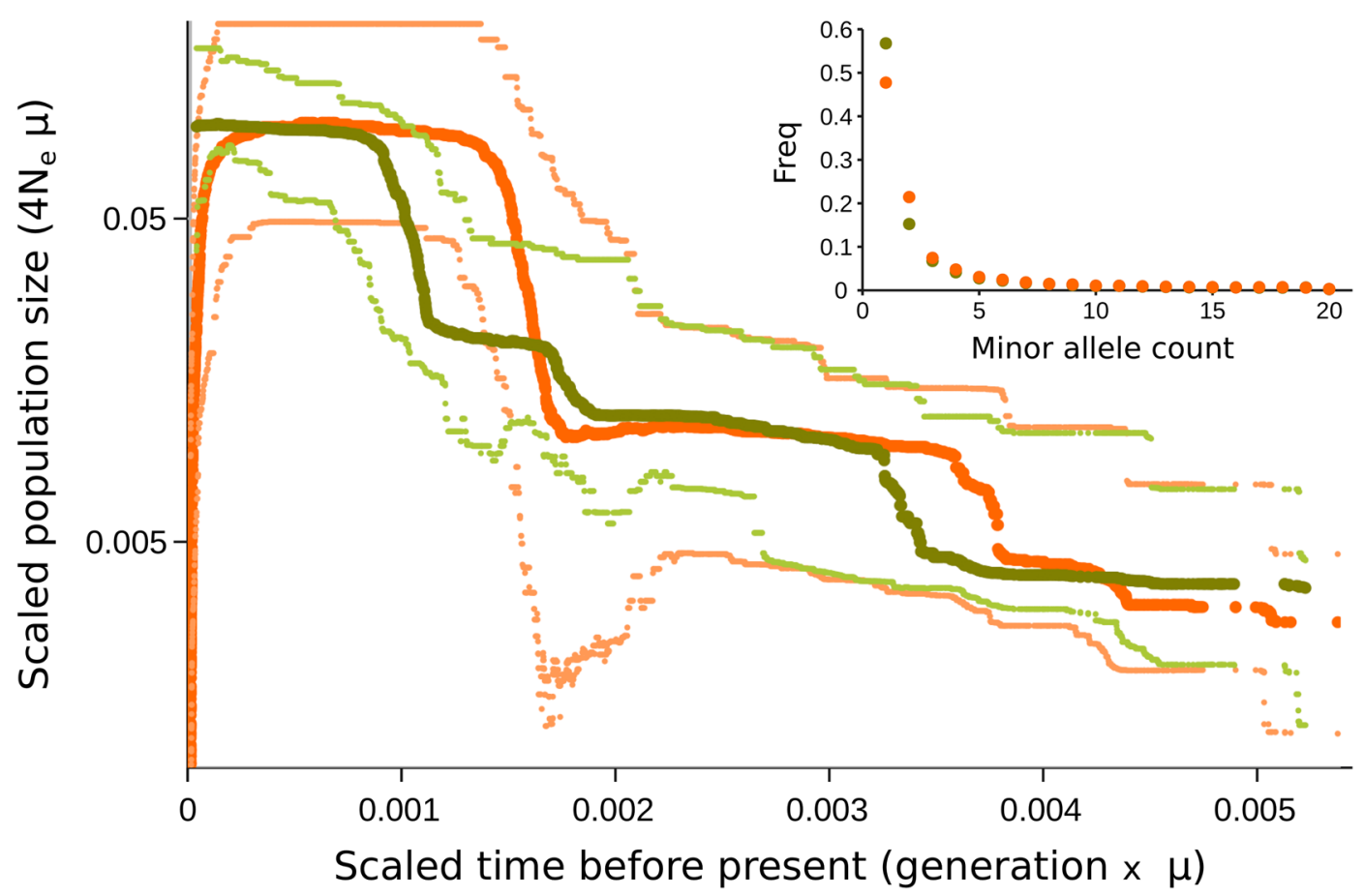

Figure 6. Demography of Adriatic (green) and Tyrrhenian (orange) populations, as inferred by a Stairway Plot. The minor allele site frequency spectrum for each population is shown in the top right (calculated on 20 individuals-see Methods). Mean (dark shade) and 95\% confidence intervals (light shade). Effective population size (y-axis; log-scale) and time before present (x-axis) are scaled by the substitution rate.

In 2014, Joaquim and coworkers ${ }^{38}$ reported that in Portugal, gametogenesis in C. gallina occurs at the same time as the increase in food availability and is able to provide energy useful for this process ${ }^{53,54}$. Moreover, recent results ${ }^{11,38}$ challenge the canonical evidence reported for the reproductive cycle of C. gallina, in which two peaks of gamete emission in April and October were described ${ }^{6-9}$. Indeed, analyses performed on natural populations of C. gallina living in the Gulf of Cadíz, as reported by Delgado and colleagues ${ }^{11}$, demonstrated a long reproductive period between March and September with a recovery of gametogenesis in November related to the high peak of chlorophyll-a availability observed in October. In addition, an intragonadal and interindividual asynchrony has been reported for the striped venus. These observations are in keeping with the timeline discrepancy in the reproduction of $C$. gallina specimens between the $S$ and SM sites. This timeline incongruence might be consistent with two possible scenarios: gametogenesis in SM clams is delayed and thus covers a shifted forward period compared to S specimens; either SM clams experienced an additional peak of gamete emission in the autumnal period. Ecotoxicological and chemical analyses supported our interpretation of transcriptomic data. Although it is known that cellular responses can be affected by environmental contaminants, the determination of chemical parameters in the clam tissues enabled us to exclude pollutants as possibly causes of observed variations in both transcriptomics and in biomarker responses. Indeed, detected bioaccumulation values were below regulatory limits for bivalve mollusks (where present) and similar to those found in C. gallina inhabiting nonpolluted areas $(\text { EC 1881/2006; EC 835/2011) })^{24,55}$.

It is known for several bivalve species that biological parameters undergo seasonal variations in natural populations not exposed to contaminated conditions; hence, the differences shown from biomarker analyses in marine organisms employed as bioindicators of environmental quality might be related to a different physiological state ${ }^{56-58}$. The results obtained in the present study highlighted that in C. gallina, the biological responses utilized as biomarkers were modulated by biotic and abiotic seasonal factors, including salinity, temperature, food availability and reproductive status, confirming again the influence of these factors on biomarker modulation in sentinel marine species ${ }^{56,59,60}$. In particular, in S clams, the higher levels of glutathione and of the activities of all glutathione-dependent antioxidant enzymes (GST, GR, Se-GPx, and total GPx) in the spring period can be related to an increased metabolic rate, as also indicated by the upregulation of energy metabolism genes, the higher phytoplankton availability and the active gonadic status. In contrast, only small variations in biological responses (in particular, CAT activity and levels of GSH and MT) were observed in SM clams between spring and autumn seasons, although a certain difference was observed at the transcriptomic level (upregulation of energy metabolism genes in autumn). This finding could be interpreted as an indication that transcriptional responses occur earlier, and they are translated into a functional effect later.

The findings discussed to this point indicate an intriguing ability of the striped venus to adapt to different environmental conditions. It is known that the adaptive potential of species to cope environmental perturbations is positively correlated with genetic diversity. Therefore, the assessment of the genetic diversity level of the striped venus natural beds has been performed to confirm that the quantitative decline experienced by C. gallina 
in the last 2 decades did not negatively affect the genetic variability and, consequently, its ability to respond to modified environments.

The results showed that striped venus individuals sampled at five different localities in the Adriatic Sea, spanning over $600 \mathrm{~km}$ (from Monfalcone (Mo) to SM), are all part of a largely panmictic population (Fig. 5), as also reported in species with high larval dispersal rates ${ }^{61-63}$ and in species with higher adult dispersal rates, such as squid and cuttlefish ${ }^{64}$. Moreover, the $F_{S T}$ between Adriatic (altogether) and Tyrrhenian localities is high compared to the differentiation recorded in the Mediterranean Basin for other marine mollusks, such as the wedge $\mathrm{clam}^{65}$, the octopus ${ }^{6,67}$ and the bivalve Pecten jacobaeus ${ }^{37}$, or more mobile fish species ${ }^{68-70}$.

The high genetic diversity recorded together with the existence of a unique population in the Adriatic Sea confers to this species a higher responsiveness to local environmental perturbations (e.g., overfishing, pollution, and mortality due to microbiological infections), as reported for invertebrate marine species ${ }^{71-73}$. Genetic interconnection due to larval dispersion between Adriatic sites represents a fundamental counterforce against local population size decline, thereby increasing the ability of population persistence ${ }^{74}$. Larval dispersion seems to have played a less important role due to the species' limited and patchy distribution along the Italian Tyrrhenian coast and to the separation from the Adriatic population. Accurate comparisons on diversity and structure are, however, limited because of the scarcity of genomic studies in Mediterranean marine invertebrates ${ }^{75}$.

Even though the striped venus fishery recorded a marked decline over the last 20 years $^{12,76}$, our demographic reconstruction showed no signature of recent decline in the Adriatic population size (Fig. 6). However, the time and population size scale of our demographic inference should be considered with caution, as we do not have precise information on the mutation rate in this organism. In fact, the extremely high genetic diversity in our ddRAD-Seq dataset could be explained by a very high effective population size and/or by a very rapid mutation $\operatorname{rate}^{75}$. At any rate, the contrast between the recent demography of the striped venus population from the Adriatic and the population from Naples, where a decline in population size has also been directly observed ${ }^{77}$, is evident (Fig. 6).

Moreover, genetic structure in sessile marine organisms is expected to be related to the length and dispersal capacity of the larval stage ${ }^{63}$ and, not negligibly, to the oceanographic barriers determined by water circulations ${ }^{62,78-80}$. In particular, in the south of the Adriatic Sea (the Strait of Otranto), a circular current of the upper water masses represents a possible constraint of C. gallina pelagic larval migration, enabling the isolation of the Adriatic one from the other Mediterranean populations. This situation has also been observed in other marine species ${ }^{63,69}$. The cause of the differentiation of the Adriatic C. gallina population from that of the Tyrrhenian Sea might also be attributed to the geodynamic evolution of the Mediterranean Basin. The oldest fossil records of the venus clam date to the Oligocene ${ }^{80}$ and the Messinian Stage in the late Miocene. Most likely, the deep biota underwent extinction, while the shallow-water biota may have survived this drastic event ${ }^{81-84}$.

\section{Conclusions}

This study provides a multidisciplinary approach that is able to provide an exhaustive view of the biological status of striped venus. Comparisons of transcriptomic and histological data between C. gallina specimens collected in two different sites of the Italian middle Adriatic coast showed a substantial temporal difference in gonadal development and gamete emission. This characteristic is likely due to the "opportunistic" behavior of C. gallina, which is able to exploit local fluctuations in nutrient availability. Ecotoxicological and chemical investigations excluded the effects of pollution and anthropic factors, suggesting a good healthy status of the striped venus. The high genetic diversity level that emerged from our ddRAD dataset analyses suggests that stock reduction has not negatively affected C. gallina natural beds. Indeed, the high larval dispersal rate might have played a "compensatory role" on local fluctuations, conferring a good adaptive potential of this species to face the environmental perturbations to which it is continuously subjected.

Therefore, elucidating the bioecological properties and the genetic diversity of wild populations is a conditio sine qua non in the field of conservation biology to adopt ad hoc management plans of fishery resources, which may also result in positive effects on the fishing economy.

\section{Materials and methods}

This study was conducted on invertebrates (molluscs), not subjected to specific permissions since the sampling area is not privately owned or protected and did not involve endangered or protected species.

Experimental sampling plan. Clams Chamelea gallina of similar size and weight $(25.4 \pm 2.1 \mathrm{~mm}$ shell length; $755 \pm 92 \mathrm{mg}$ body wet weight) were collected by hydraulic dredge, in different sites and periods.

For population genetics analyses, 155 specimens were sampled from five sites (Fig. 7, coordinates Marcelli of

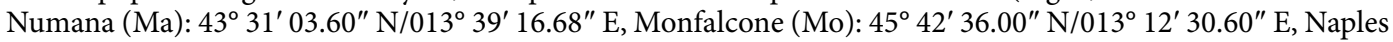
$(\mathrm{N}): 40^{\circ} 49^{\prime} 12.00^{\prime \prime} \mathrm{N} / 014^{\circ} 02^{\prime} 24.00^{\prime \prime}$ E, Senigallia (S): $43^{\circ} 41^{\prime} 01.38^{\prime \prime} \mathrm{N} / 013^{\circ} 17^{\prime} 48.72^{\prime \prime}$ E, Silvi Marina (SM): $42^{\circ}$ 33' 19.92" N/014 08'01.26" E).

Concerning transcriptomic, ecotoxicological, chemical, and histological analyses, specimens of the two sampling sites, S and SM, were collected in late spring and autumn 2018. In particular, for transcriptomic analyses, three pools of digestive glands dissected from 10 specimens were analysed for each sampling site and period; for histological analyses 20 specimens for each sampling site were examined to determine the stage of gonadal development. Ecotoxicological and chemical analyses required a total of 235 specimens for each sampling group: whole tissue was collected from 30 individuals for the calculation of Condition Index (CI = [dry tissue weight $(\mathrm{g}) /$ dry shell weight $(\mathrm{g})] \times 100)^{85}$; fresh hemolymph was taken from 5 specimens for the analysis of lysosomal membrane stability; 5 pools of digestive gland and hemolymph (10 organisms per pool) were frozen in liquid 


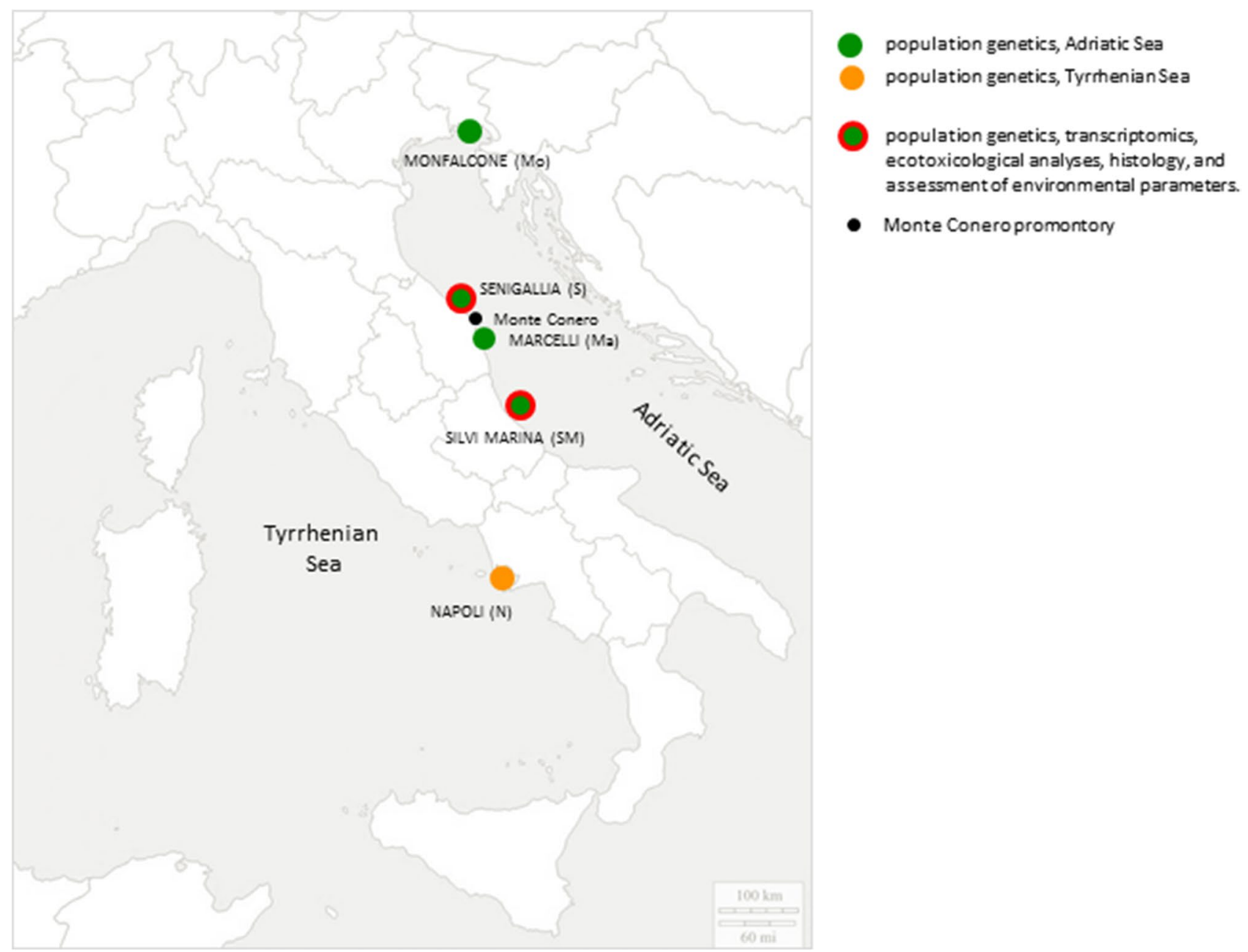

Figure 7. Sampling and experimental plan. Specimens collected from Monfalcone (Mo), Senigallia (S), Marcelli (Ma), Silvi Marina (SM), and Napoli (N) sampling sites were investigated through population genetics (dark green dots: sampling sites located in the Adriatic Sea; orange dot: sampling site located in the Tyrrhenian Sea; black dot: Monte Conero promontory). Transcriptomics, histology, ecotoxicological analyses, and assessment of environmental parameters were performed on samples collected from S and SM sampling sites (red circled dark green dots).

nitrogen and stored at $-80^{\circ} \mathrm{C}$ for ecotoxicological analyses (biomarkers); 3 pools of whole tissues (50 organisms per pool) were collected for chemical analyses of bioaccumulation.

Transcriptomic analyses: sequencing and bioinformatics analyses. Total RNA was extracted using Trizol reagent (Invitrogen, ThermoFisher Scientific) and purity and quantity were checked using Qubit 4.0 fluorometer (ThermoFisher Scientific). RNA integrity was evaluated by Agilent 2100 Bioanalyzer (Agilent technologies, Santa Clara, CA). RNAs were sent to IGA Technology Service (Udine, Italy; https://igatechnology. com) where TruSeq Stranded mRNA Sample Prep kit (Illumina, San Diego, CA) was used for library preparation following the manufacturer's instructions, starting with $1 \mu \mathrm{g}$ of good quality RNA (R.I.N $>7$ ) as input. The poly-A mRNA was fragmented $3 \mathrm{~min}$ at $94^{\circ} \mathrm{C}$ and every purification step was performed by using $1 \times$ Agencourt AMPure XP beads. Libraries were then processed with Illumina cBot for cluster generation on the flowcell, following the manufacturer's instructions and sequenced on $2 \times 125$ bp paired-end mode on HiSeq2500 (Illumina, San Diego, CA).

Gene expression analysis. The Bcl2Fastq 2.0.2 version of the Illumina pipeline was used to process raw data for both format conversion and de-multiplexing. Removing lower quality bases and adapters was carried out using ERNE ${ }^{86}$ and Cutadapt ${ }^{87}$ softwares. Trimmed RNA-Seq reads of each sample were mapped on the C. gallina reference transcriptome ${ }^{28}$ using $\mathrm{STAR}^{88}$. After performing the assembly and quantification of the full-length transcripts using StringTie ${ }^{89}$, the count of overlapping reads was performed with HTseq count ${ }^{90}$. DESeq $2^{91}$ was used to perform comparisons between expression levels of genes and transcripts as follow: $\mathrm{S}$ spring versus $S$ autumn; SM spring versus SM autumn; S spring versus SM spring; $S$ autumn versus SM autumn (Supplementary Fig. S1). 
Contigs obtained from comparative analyses conducted using DESeq2 were used to perform functional annotation and pathway enrichment analyses. From each comparison, genes were filtered using the Benjamini-Hochberg adjusted $p$ value $<0.01$, genes showing a negative $\log _{2}$ fold change value were considered as downregulated while those with a positive $\log _{2}$ fold change value were considered as upregulated. CLC genomic workbench v12.0 (Qiagen, Hilden, Germany) was then used to perform domain search in PFAM database v32 ${ }^{92}$. Functional enrichment analysis was performed with KEGG BlastKOALA ${ }^{93-95}$ (https://www.kegg.jp/blastkoala/).

Hystological analyses. Gonadal tissues of specimens from S and SM were histologically examined to determine the stage of gonadal development. After embedding in Killik (Bio-Optica, Milano, Italy) medium, sections of $8-10 \mu \mathrm{m}$ were obtained using Leica cryostat (Wetzlar, Germany). The histology prepared slides were stained with haematoxylin and eosin method and inspected using the optical light microscope (Olympus Co., Tokyo, Japan).

Ecotoxicological and chemical analyses. Ecotoxicological analyses (biomarker) analyses were carried out through standardized procedures and included: Condition Index (CI) calculation; analysis of lysosomal membrane stability in the hemocytes; spectrophotometric determination of acetylcholinesterase activity in the hemolymph; spectrophotometric determination of single antioxidants (catalase, glutathione S-transferases, glutathione peroxidases and glutathione reductase activity; total glutathione content) and gas-chromatographic assay of total antioxidant scavenging capacity toward peroxyl and hydroxyl radicals ${ }^{96,97}$; metallothioneins level ${ }^{98}$.

Chemical analyses of trace metals (As, $\mathrm{Cd}, \mathrm{Cr}, \mathrm{Cu}, \mathrm{Fe}, \mathrm{Hg}, \mathrm{Mn}, \mathrm{Ni}, \mathrm{Pb}, \mathrm{V}, \mathrm{Zn}$ ) and polycyclic aromatic hydrocarbons (PAHs), both low molecular weight (naphthalene, acenaphthylene, 1-metylnaphthalene, 2-metylnaphthalene, acenaphthene, fluorene, phenanthrene, anthracene) and high molecular weight (fluoranthene, pyrene, benzo[a]anthracene, chrysene, 7,12-dimetylbenzo[a] anthracene, benzo[b]fluoranthene, benzo[k]fluoranthene, benzo[a]pyrene, dibenzo[a,h] anthracene, benzo[g,h,i]perylene, indeno[1,2,3,c,d]pyrene) were performed on whole clam tissues by conventional procedures base on gas-chromatography with flame ionization detector, HPLC with fluorimetric detection, and atomic absorption spectrophotometry ${ }^{99}$.

Details of analytical procedures for both ecotoxicological and chemical analyses are given in Supplementary File S1.

Statistical comparison of biological parameters was performed through the analysis of variance (ANOVA) with a level of significance set at $p<0.05$, and the post hoc comparison Newman-Keuls. The analyses were performed with the R software.

Assessment of environmental parameters. Historical timeseries of temperature, salinity and chlorophyll concentration are taken from the output of hydrodynamics and biogeochemical models of the Mediterranean Sea, publicly available on E.U. Copernicus Marine Service Information (https://marine.copernicus.eu). Temperature and salinity were extracted from the Mediterranean Sea Physics Analysis and Forecast dataset ${ }^{100}$ which nowadays represents the best available estimate of the physical environment and dynamics of the whole Mediterranean Sea. Chlorophyll timeseries were extracted from the Mediterranean Sea Biogeochemistry Analysis and Forecast dataset ${ }^{101}$ which is produced by a biogeochemical fluxes model, named MedBFM, driven by physical forcing fields from the aforementioned analysis and forecast dataset. Extracted timeseries span the year 2018. Data were provided as daily means for temperature, salinity, and chlorophyll. The model grid sea-points nearest to S and SM sampling stations were chosen and data were extracted at the sea-floor level. Seasonal means of the year 2018 were calculated and further processed with the aim to check if the two sampling stations exhibit significant differences in terms of monthly and seasonal means of the parameters taken into account. The assessment was performed by applying a one-way analysis of variance (ANOVA) and a Tukey's test as post-hoc pairwise comparison. The null hypothesis stated that there were no differences in terms of temperature, salinity or chlorophyll concentration between the two sampling stations. The level of significance was set at 0.05 . The software Unistat 10 was used to perform the analysis.

Population genetics: sequencing and bioinformatics analyses. Total DNA extraction from foot tissue was performed for 48 individuals of each sampling site (Fig. 7) using DNeasy Blood and Tissue Kit (Qiagen). Information on the sex of animals were not recorded. After total extraction, purity and quantity of total DNA extracted were checked using Qubit 4.0 fluorometer (Thermo Fisher Scientific). DNA samples were sent to IGA Technology Service (Udine, Italy; https://igatechnology.com) where ddRAD libraries were produced using IGATech custom protocol, with minor modifications of Peterson's and colleagues $(2012)^{102}$. Libraries were constructed using SphI and HindIII restriction enzymes and sequenced with V4 chemistry paired end 125 bp mode on HiSeq2500 instrument (Illumina, San Diego, CA).

Raw reads were demultiplexed by process_radtags in Stacks $2.4^{103}$ with default settings. Paired-end reads from all individuals were de novo assembled using the script denovo_map.pl in the Stacks package, allowing for maximum two mismatches between stacks to call a locus within and among individuals (-M 2 and $-\mathrm{n} 2$ ), disabling haplotype calling from secondary reads $(-\mathrm{H})$ and setting the maximum number of stacks at locus to 2 (-max_locus_stacks). The script populations in the Stacks package was employed to discard loci found in less than $40 \%$ of individuals across all populations $(-\mathrm{R}=0.4)$ and with observed heterozygosity higher than 0.8 (-max-obs-het). Before any downstream analysis, our dataset for contamination by non-endogenous DNA was tested. Blast ${ }^{104}$ was used to map the consensus sequence of each locus to $n t$ database (downloaded on 14/09/19) applying an epsilon threshold of 1e-04. Blast results were taxonomically summarized using MEGAN ${ }^{105}$ (Supplementary Fig. S4). The catalog of loci was then further reduced, first excluding individuals with more the $50 \%$ missing loci and then loci with more than $25 \%$ missing individuals. 
The scripts Stacks2fineRAD.py included in the fineRADstructure package ${ }^{106}$ was used to estimate the distribution of alleles and SNPs per locus and of the missing data per individual. As ddRAD is prone to batch effect due to small deviations among libraries at the size selection step, we checked whether missing data were driving any library-based structure. A PCA analysis converting all loci in presence/absence data was performed using the same script as before. Beside any batch effect, allele drop-out due to genetic differentiation among individuals was also evident with this analysis. To investigate the genetic structure in our sample and to test for its robustness to missing data and number of SNPs per locus, fineRADstructure after filtering the data with different settings in Stacks2fineRAD.py was used. In particular, the analysis with a full dataset (2004 loci and 155 individuals) was run, selecting only loci with less than 45 SNPs (918 loci), selecting individuals with less than $25 \%$ missing data (147 individuals), and the combination of both filters (918 loci and 145 individuals-individuals were filtered after the loci).

The folded site frequency spectrum (SFS) was calculated in each of the two populations inferred by fineRADstructure using a custom python script (Supplementary File S2), normalized over 20 individuals to take into account the sampling difference between the two populations, and not allowing for missing data. Average number of nucleotide pairwise differences $(\pi)$ per locus was calculated within each population using $v c f t o o l s s^{107}$ and considering an average locus length of $230 \mathrm{bp}$. Weighted $F_{S T}$ between the two populations was also calculated using vcftools.

To separately infer the past demographic histories of the two populations, we used the SFS as calculated before in Stairway $\mathrm{Plot}^{108}$, a model-free method to infer the variation in past coalescent rate within a population through the maximization of the composite likelihood of the site frequency spectrum. The total number of observed sites was calculated as the number of loci times an average locus length of $230 \mathrm{bp}$ and all bins of the SFS were used given the high confidence in heterozygous sites calling due to the high coverage per locus. As mutation rate is not known in this species, time and population size of the demographic reconstruction are given as scaled by the mutation rate.

\section{Data accessibility}

ddRAD and RNA-Seq dara are deposited in SRA database (BioProject PRJNA625642 and PRJNA625643, respectively). Historical timeseries of temperature, salinity and chlorophyll concentration are publicly available from the output of hydrodynamics and biogeochemical models of the Mediterranean Sea, on E.U. Copernicus Marine Service Information (https://marine.copernicus.eu).

Received: 9 July 2020; Accepted: 30 September 2020

Published online: 05 November 2020

\section{References}

1. Ghiselli, F. et al. Comparative transcriptomics in two bivalve species offers different perspectives on the evolution of sex-biased genes. Genome Biol. Evol. 10, 1389-1402. https://doi.org/10.1093/gbe/evy082 (2018).

2. Connon, R. E., Jeffries, K. M., Komoroske, L. M., Todgham, A. E. \& Fangue, N. A. The utility of transcriptomics in fish conservation. J. Exp. Biol. 221, jeb148833 (2018).

3. Gaspar, M. B. \& Monteiro, C. C. Reproductive cycles of the razor clam Ensis siliqua and the clam Venus striatula off Vilamoura Southern Portugal. J. Mar. Biol. Assoc. U.K. 78, 1247-1258 (1998).

4. Poppe, G. T. \& Goto, Y. European Seashells. Vol II (Scaphopoda, Bivalvia, Cephalopoda) 1-221 (Verlag Christa Hemmen, Germany, 1993).

5. Orban, E. et al. Nutritional and commercial quality of the striped venus clam, Chamelea gallina, from the Adriatic sea. Food Chem. 101, 1063-1070 (2007).

6. Casali, C. Résumé des paramètres biologiques sur Venus gallina L. en Adriatique (Synopsis of biological data on Venus gallina L. in the Adriatic Sea). FAO Fish. Rep. 290, 171-173 (1984).

7. Froglia, C. Aspetti biologici, tecnologici e statistici della pesca delle vongole (Venus gallina) (Biological, technological and statistical observations on the fishery targeting common clams, Venus gallina). Incontri Tecnici, Laboratorio di Tecnologia della Pesca, Consiglio Nazionale delle Ricerche. 9, 7-22 (1975).

8. Keller, N., Del Piero, D. \& Longinelli, A. Isotopic composition, growth rates and biological behaviour of Chamelea gallina and Callista chione in the Gulf of Trieste. Mar. Biol. 140, 9-15 (2002).

9. Valli, G., Zardini, D. \& Nodari, P. Cycle reproductif et biométrie chez Chamelea gallina (L.) (Mollusca, Bivalvia) dans le Golfe de Trieste (Reproductive cycle and biometry of the Chamelea gallina stock in the Gulf of Trieste). Rapp. Comm. Int. Mer Méditerr. 29, 339-340 (1985).

10. Dalgiç, G., Okumuş, I. \& Karayücel, S. The effect of fishing on growth of the clam Chamelea gallina (Bivalvia: Veneridae) for the Turkish Black Sea coast. J. Mar. Biol. Assoc. UK 90, 261-265 (2009).

11. Delgado, M., Silva, L. \& Juárez, A. Aspects of reproduction of striped venus Chamelea gallina in the Gulf of Cádiz (SW Spain): implications for fishery management. Fish. Res. 146, 86-95 (2013).

12. Romanelli, M., Cordisco, C. A. \& Giovanardi, O. The long-term decline of the Chamelea gallina L. (Bivalvia: Veneridae) clam fishery in the Adriatic Sea: is a synthesis possible?. Acta Adriat. 50, 171-205 (2009).

13. Ministerial decree n.27 del 17/6/(2019), Ministry of Agricultural Food, forestry, and Tourism policies. Adozione del Piano di gestione nazionale per le attivita' di pesca con il sistema draghe idrauliche e rastrelli da natante così come identificati nella denominazione degli attrezzi di pesca in draghe meccaniche comprese le turbosoffianti (HMD) e draga meccanizzata (DRB). (2019), Gazzetta ufficiale Italiana.

14. Vaughn, C. C. \& Hoellein, T. J. Bivalve impacts in freshwater and marine ecosystems. Annu. Rev. Ecol. Evol. Syst. 49, 183-208 (2018).

15. Fitzer, S. C., Phoenix, V. R., Cusack, M. \& Kamenos, N. A. Ocean acidification impacts mussel control on biomineralisation. Sci. Rep. 4, 6218 (2014).

16. Li, Q., Zhao, X., Khong, L. \& Yu, H. Transcriptomic response to stress in marine bivalves. Invert. Surviv. J. 10, $84-93$ (2013).

17. Luchmann, K. H. et al. Biochemical biomarkers and hydrocarbons concentrations in the mangrove oyster Crassostrea brasiliana following exposure to diesel fuel water-accommodated fraction. Aquat. Toxicol. 105, 652-660 (2011).

18. Philipp, E. E. et al. Massively parallel RNA sequencing identifies a complex immune gene repertoire in the lophotrochozoan Mytilus edulis. PLoS ONE 7, e33091 (2012). 
19. Ezgeta-Balic, D. et al. An energy budget for the subtidal bivalve Modiolus barbatus (Mollusca) at different temperatures. Mar. Environ. Res. 71, 79-85 (2011).

20. Ivanina, A. V., Kurochkin, I. O., Leamy, L. \& Sokolova, I. M. Effects of temperature and cadmium exposure on the mitochondria of oysters (Crassostrea virginica) exposed to hypoxia and subsequent reoxygenation. J. Exp. Biol. 215, 3142-3154 (2012).

21. Matozzo, V. et al. First evidence of immunomodulation in bivalves under seawater acidification and increased temperature. PLoS ONE 7(3), e33820. https://doi.org/10.1371/journal.pone.0033820 (2012).

22. Monari, M., Foschi, J., Rosmini, R., Marin, M. G. \& Serrazanetti, G. P. Heat shock protein 70 response to physical and chemical stress in Chamelea gallina. J. Exp. Mar. Biol. Ecol. 397, 71-78 (2011).

23. Sobral, P. \& Widdows, J. Influence of hypoxia and anoxia on the physiological response of the clam Ruditapes decussatus from southern Portugal. Mar. Biol. 127, 455-461 (1997).

24. Visciano, P. et al. Concentrations of contaminants with regulatory limits in samples of clam (Chamelea gallina) collected along the Abruzzi Region Coast in Central Italy. J. Food Prot. 78, 1719-1728 (2015).

25. Moschino, V., Deppieri, M. \& Marin, M. G. Evaluation of shell damage to the clam Chamelea gallina captured by hydraulic dredging in the Northern Adriatic Sea. ICES J. Mar. Sci. 60(2), 393-401 (2003).

26. Milan, M. et al. Transcriptomic profiling of Chamelea gallina from sites along the Abruzzo coast (Italy), subject to periodic localized mortality events. Mar. Biol. 163, 163-169 (2016).

27. Milan, M. et al. Host-microbiota interactions shed light on mortality events in the striped venus clam Chamelea gallina. Mol. Ecol. 28, 4486-4499 (2019).

28. Coppe, A. et al. Sequencing and characterization of striped venus transcriptome expand resources for clam fishery genetics. PLoS ONE 7(9), e44185 (2012).

29. Papetti, C. et al. Genetic variability of the striped venus Chamelea gallina in the northern Adriatic Sea. Fish. Res. 201, 68-78 (2018).

30. Eizaguirre, C. \& Baltazar-Soares, M. Evolutionary conservation-evaluating the adaptive potential of species. Evol. Appl. 7, 963-967 (2014)

31. Mable, B. K. Conservation of adaptive potential and functional diversity: integrating old and new approaches. Conserv. Genet. 20, 89-100 (2019).

32. He, X., Johansson, M. L. \& Heath, D. D. Role of genomics and transcriptomics in selection of reintroduction source populations. Conserv. Biol. 30, 1010-1018 (2016).

33. Bertucci, A. et al. Transcriptomic responses of the endangered freshwater mussel Margaritifera margaritifera to trace metal contamination in the Dronne River France. Environ. Sci. Pollut. R. 24, 27145-27159 (2017).

34. Gonzalez, P. \& Pierron, F. Omics in aquatic ecotoxicology: the ultimate response to biological questions? In aquatic ecotoxicology (eds Amiard, J. C. et al.) 183-203 (Academic Press, Cambridge, 2015). https://doi.org/10.1016/B978-0-12-800949-9.00008-5.

35. Milan, M. et al. Ecotoxicological effects of the herbicide glyphosate in non-target aquatic species: transcriptional responses in the mussel Mytilus galloprovincialis. Environ. Pollut. 237, 442-451 (2018).

36. Vendrami, D. L. J. et al. RAD sequencing resolves fine-scale population structure in a benthic invertebrate: implications for understanding phenotypic plasticity. R. Soc. Open Sci. 4, 160548 (2017).

37. Vendrami, D. L. J. et al. RAD sequencing sheds new light on the genetic structure and local adaptation of European scallops and resolves their demographic histories. Sci. Rep. 9, 7455 (2019).

38. Joaquim, S. et al. Biochemical and energy dynamics throughout the reproductive cycle of the striped venus Chamelea gallina (Mollusca, Bivalvia). Invertebr. Reprod. Dev. 58, 284-293 (2014).

39. Hamdani, A. \& Soltani-Mazouni, N. Changes in biochemical composition of the gonads of Donax trunculus L. (Mollusca, Bivalvia) from the Gulf of Annaba (Algeria) in relation to reproductive events and pollution. Jordan J. Biol. Sci. 4, 149-156 (2011).

40. Mancuso, A. et al. Environmental influence on calcification of the bivalve Chamelea gallina along a latitudinal gradient in the Adriatic Sea. Sci. Rep. 9, 11198 (2019).

41. Artegiani, A. et al. The Adriatic Sea general circulation. Part II: baroclinic circulation structure. J. Phys. Oceanogr. 27, 1515-1532 (1997).

42. Wold, S., Esbensen, K. \& Geladi, P. Principal component analysis. Chemometr. Intell. Lab. 2, 37-52 (1987).

43. Bianchi, C. N. \& Morri, C. Marine biodiversity of the Mediterranean Sea: situation, problems and prospects for future research. Mar. Pollut. Bull. 40, 367-376 (2000)

44. Nakayama, K. I. \& Nakayama, K. Ubiquitin ligases: cell-cycle control and cancer. Nat. Rev. Cancer 6, 369-381 (2006).

45. Mackintosh, C. Dynamic interactions between 14-3-3 proteins and phosphoproteins regulate diverse cellular processes. Biochem. J. 15, 329-342 (2004).

46. Gardino, A. K. \& Yaffe, M. B. 14-3-3 Proteins as signaling integration points for cell cycle control and apoptosis. Semin. Cell. Dev. Biol. 22, 688-695 (2012).

47. Telles, E., Hosing, A. S., Kundu, S. T., Venkatraman, P. \& Dalal, S. N. A novel pocket in 14-3-3epsilon is required to mediate specific complex formation with cdc25C and to inhibit cell cycle progression upon activation of checkpoint pathways. Exp. Cell. Res. 315, 1448-1457 (2009).

48. Llera-Herrera, R., Garcia-Gasca, A., Abreu-Goodger, C., Huvet, A. \& Ibarra, A. M. Identification of male gametogenesis expressed genes from the scallop Nodipecten subnodosus by suppressive subtraction hybridization and pyrosequencing. PLoS ONE 8(9), e73176 (2013)

49. Lucas, A. \& Beninger, P. G. The use of physiological condition indices in marine bivalve aquaculture. Aquaculture 44, 187-200 (1985).

50. Artigaud, S. et al. Deciphering the molecular adaptation of the king scallop (Pecten maximus) to heat stress using transcriptomics and proteomics. BMC Genom. 16, 988 (2015).

51. Clark, M. S. et al. Identification of molecular and physiological responses to chronic environmental challenge in an invasive species: the Pacific oyster Crassostrea gigas. Ecol. Evol. 3, 3283-3297 (2013).

52. Lockwood, B. L., Sanders, J. G. \& Somero, G. N. Transcriptomic responses to heat stress in invasive and native blue mussels (genus Mytilus): molecular correlates of invasive success. J. Exp. Biol. 213, 3548-3558 (2010).

53. Darriba, S., San Juan, F. \& Guerra, A. Energy storage and utilization in relation to the reproductive cycle in the razor clam. ICES J. Mar. Sci. 62, 886-896 (2005).

54. Mathieu, M. \& Lubet, P. Storage tissue metabolism and reproduction in marine bivalves: a brief review. Invertebr. Reprod. Dev. 23, 123-129 (1993).

55. Usero, J., Morillo, J. \& El Bakouri, H. A general integrated ecotoxicological method for marine sediment quality assessment: application to sediments from littoral ecosystems on Southern Spain's Atlantic coast. Mar. Pollut. Bull. 56, 2027-2036 (2008).

56. Bocchetti, R. \& Regoli, F. Seasonal variability of oxidative biomarkers, lysosomal parameters, metallothioneins and peroxisomal enzymes in the Mediterranean mussel Mytilus galloprovincialis from Adriatic Sea. Chemosphere 65, 913-921 (2006).

57. Nahrgang, J. et al. Seasonal variation in biomarkers in blue mussel (Mytilus edulis), Icelandic scallop (Chlamys islandica) and Atlantic cod (Gadus morhua)-Implications for environmental monitoring in the Barents Sea. Aquat. Toxicol. 127, 21-35 (2013).

58. Sardi, A. E., Renaud, P. E., da Cunha Lanna, P. \& Camus, L. Baseline levels of oxidative stress biomarkers in species from a subtropical estuarine system (Paranaguá Bay, southern Brazil). Mar. Pollut. Bull. 113, 496-508 (2016). 
59. Gorbi, S., Baldini, C. \& Regoli, F. Seasonal variability of metallothioneins, cytochrome P450, bile metabolites and oxyradical metabolism in the European eel Anguilla anguilla L. (Anguillidae) and striped mullet Mugil cephalus L. (Mugilidae). Arch. Environ. Con. Tox. 49, 62-70 (2005).

60. Gorbi, S. et al. An ecotoxicological protocol with caged mussels, Mytilus galloprovincialis, for monitoring the impact of an offshore platform in the Adriatic Sea. Mar. Environ. Res. 65, 34-49 (2008).

61. Fernández, R., Lemer, S., McIntyre, E. \& Giribet, G. Comparative phylogeography and population genetic structure of three widespread mollusc species in the Mediterranean and near Atlantic. Mar. Ecol. 36, 701-715 (2015).

62. Lourenço, C. R. et al. Evidence for rangewide panmixia despite multiple barriers to dispersal in a marine mussel. Sci. Rep. 7, 10279 (2017).

63. Villamor, A., Costantini, F. \& Abbiati, M. Genetic structuring across marine biogeographic boundaries in rocky shore invertebrates. PLoS ONE 9, e101135 (2014)

64. Garoia, F. et al. Microsatellite DNA variation reveals high gene flow and panmictic populations in the Adriatic shared stocks of the European squid and cuttlefish (Cephalopoda). Heredity 93, 166-174 (2004).

65. Marie, A. D. et al. Implications for management and conservation of the population genetic structure of the wedge clam Donax trunculus across two biogeographic boundaries. Sci. Rep. 6, 39152 (2016).

66. De Luca, D., Catanese, G., Procaccini, G. \& Fiorito, G. Octopus vulgaris (Cuvier, 1797) in the Mediterranean Sea: genetic diversity and population structure. PLoS ONE 11(2), e0149496 (2016).

67. Melis, R. et al. Genetic population structure and phylogeny of the common octopus Octopus vulgaris Cuvier, 1797 in the western Mediterranean Sea through nuclear and mitochondrial markers. Hydrobiologia 807, 277-296 (2018).

68. Bahri-Sfar, L., Lemaire, C., Hassine, O. K. B. \& Bonhomme, F. Fragmentation of sea bass populations in the Western and Eastern Mediterranean as revealed by microsatellite polymorphism. Proc. R. Soc. Lond. 267, 929-935 (2000)

69. Maggio, T., Lo Brutto, S., Garoia, F., Tinti, F. \& Arculeo, M. Microsatellite analysis of red mullet Mullus barbatus (Perciformes, Mullidae) reveals the isolation of the Adriatic Basin in the Mediterranean Sea. ICES J. Mar. Sci. 66, 1883-1891 (2009).

70. Schunter, C. et al. Matching genetics with oceanography: directional gene flow in a Mediterranean fish species. Mol. Ecol. 20, 5167-5181 (2011).

71. Aguirre, J. D. \& Marshall, D. J. Genetic diversity increases population productivity in a sessile marine invertebrate. Ecology 93, $1134-1142$ (2012)

72. Gamfeldt, L. \& Källström, B. Increasing intraspecific diversity increases predictability in population survival in the face of perturbations. Oikos 116, 700-705 (2007).

73. Lloyd, M. M., Makukhov, A. D. \& Pespeni, M. H. Loss of genetic diversity as a consequence of selection in response to high $\mathrm{pCO}_{2}$. Evol. Appl. 9, 1124-1132 (2016).

74. Griffiths, S. M., Taylor-Cox, E. D., Behringer, D. C., Butler, M. J. IV. \& Preziosi, R. F. Using genetics to inform restoration and predict resilience in declining populations of a keystone marine sponge. Biodivers. Conserv. 29, 1383-1410 (2020).

75. Plough, L. V. Genetic load in marine animals: a review. Curr. Zool. 62, 567-579 (2016).

76. Biondi, S. \& Del Piero, D. Survey on Chamelea gallina beds in the Lignano area (Gulf of Trieste, Adriatic Sea). Ann. Istrian Mediterr. Stud. 22, 1-8 (2012).

77. Nojima, S. \& Russo, G. F. Struttura della popolazione del bivalve Chamelea gallina(L.) in un fondo sabbioso dell'isola di Ischia (Golfo di Napoli) (Population structure of Chamelea gallinain infralittoral sand off Ischia Island, Gulf of Naples). Oebalia 15, 189-201 (1989).

78. Artegiani, A. et al. The Adriatic Sea general circulation. Part I: air-sea interactions and water mass structure. J. Phys. Oceanogr. 27, 1492-1514 (1997).

79. El Ayari, T., El Menif, N. T., Hamer, B., Cahill, A. E. \& Bierne, N. The hidden side of a major marine biogeographic boundary: a wide mosaic hybrid zone at the Atlantic-Mediterranean divide reveals the complex interaction between natural and genetic barriers in mussels. Heredity 122, 70-784 (2019).

80. Keen, A. M. Veneridae. In Treatise of Invertebrate Paleontology (ed. Moore, R. C.) N671-N688 (Geological Society of America University of Kansas Press Lawrence, Boulder, 1969).

81. Bellan-Santini, D., Fredj, G. \& Bellan, G. Mise au point sur les connaissance concernant le benthos profond Mediterraneen. Oebalia 17, 21-36 (1992).

82. Bouchet, P. \& Taviani, M. The Mediterranean deep-sea fauna: pseudopopulations of Atlantic species?. Deep-Sea Res. 39, 169-184 (1992).

83. Myers, A. A. Species and generic gamma-scale diversity in shallow-water marine Amphipoda with particular reference to the Mediterranean. J. Mar. Biol. Assoc. UK 76, 195-202 (1996).

84. Stanley, D. J. \& Wezel, F.-C. Geological Evolution of the Mediterranean Basin (Springer, New York, 1985).

85. Walne, P. R. Factors affecting the relation between feeding and growth in bivalves. In Harvesting Polluted Waters Vol. 8 (ed. Devil, O.) 169-176 (Plenum Press, New York, 1976).

86. Del Fabbro, C., Scalabrin, S., Morgante, M. \& Giorgi, F. M. An extensive evaluation of read trimming effects on Illumina NGS data analysis. PLoS ONE 8(12), e85024 (2013).

87. Martin, M. Cutadapt removes adapter sequences from high-throughput sequencing reads. EMBnet. J. 17, 10-12 (2011).

88. Dobin, A. et al. STAR: ultrafast universal RNA-seq aligner. Bioinformatics 29, 15-21 (2013).

89. Pertea, M. et al. StringTie enables improved reconstruction of a transcriptome from RNA-Seq reads. Nat. Biotechnol. 33, 290-295 (2015).

90. Anders, S., Pyl, P. T. \& Huber, W. HTSeq-a Python framework to work with high-throughput sequencing data. Bioinformatics 31, 166-169 (2015).

91. Love, M., Huber, W. \& Anders, S. Moderated estimation of fold change and dispersion for RNA-seq data with DESeq2. Genome Biol. 15, 550 (2014).

92. Punta, M. et al. The Pfam protein families database. Nucleic Acid Res. 40, 290-301 (2012).

93. Kanehisa, M. \& Goto, S. KEGG: Kyoto Encyclopedia of genes and genomes. Nucleic Acids Res. 28, 27-30 (2000).

94. Kanehisa, M., Sato, Y., Furumichi, M., Morishima, K. \& Tanabe, M. New approach for understanding genome variations in KEGG. Nucleic Acids Res. 47, D590-595 (2019).

95. Kanehisa, M. Toward understanding the origin and evolution of cellular organisms. Protein Sci. 28, 1947-1951 (2019).

96. Bocchetti, R. et al. Contaminant accumulation and biomarker responses in caged mussels, Mytilus galloprovincialis, to evaluate bioavailability and toxicological effects of remobilized chemicals during dredging and disposal operations in harbour areas. Aquat. Toxicol. 89, 257-266 (2008).

97. Bocchetti, R. et al. Seasonal variations of exposure biomarkers, oxidative stress responses and cell damage in the clams, Tapes philippinarum, and mussels, Mytilus galloprovincialis, from Adriatic Sea. Mar. Environ. R. 66, 24-26 (2008).

98. Viarengo, A., Ponzano, E., Dondero, F. \& Fabbri, R. A simple spectrophotometric method for metallothionein evaluation in marine organisms: an application to Mediterranean and Antarctic molluscs. Mar. Environ. Res. 44, 69-84 (1997).

99. Fattorini, D. et al. Seasonal, spatial and inter-annual variations of trace metals in mussels from the Adriatic Sea: a regional gradient for arsenic and implications for monitoring the impact of off-shore activities. Chemosphere 72, 1524-1533 (2008). 
100. Clementi, E. et al. Mediterranean Sea Analysis and Forecast (CMEMS MED-Currents, EAS5 system). Copernicus Monitoring Environment Marine Service (CMEMS) (2019). https://doi.org/10.25423/CMCC/MEDSEA_ANALYSIS_FOREC AST_PHY_006_013_EAS5.

101. Bolzon, G. et al. Mediterranean Sea Biogeochemical Analysis and Forecast (CMEMS MED-Biogeochemistry (2018)-Present). Copernicus Monitoring Environment Marine Service (CMEMS) (2020). https://doi.org/10.25423/CMCC/MEDSEA_ANALY SIS_FORECAST_BIO_006_014_MEDBFM3.

102. Peterson, B. K., Weber, J. N., Kay, E. H., Fisher, H. S. \& Hoekstra, H. E. Double digest RADseq: an inexpensive method for de novo SNP discovery and genotyping in model and non-model species. PLoS ONE 7(5), e37135 (2012).

103. Rochette, N. C., Rivera-Colón, A. G. \& Catchen, J. M. Stacks 2: analytical methods for paired-end sequencing improve RADseqbased population genomics. Mol. Ecol. 28, 4737-4754 (2019).

104. Camacho, C. et al. BLAST+: architecture and applications. BMC Bioinformatics 10, 421 (2009).

105. Huson, D. H. et al. MEGAN community edition-interactive exploration and analysis of large-scale microbiome sequencing data. PLoS Comput. Biol. 12(6), e1004957 (2016).

106. Malinsky, M., Trucchi, E., Lawson, D. J. \& Falush, D. RADpainter and fineRADstructure: population inference from RADseq data. Mol. Biol. Evol. 35, 1284-1290 (2018).

107. Danecek, P. et al. The variant call format and VCFtools. Bioinformatics 27, 2156-2158 (2011).

108. Liu, X. \& Fu, Y.-X. Exploring population size changes using SNP frequency spectra. Nat. Genet. 47, 555-559. https://doi. org/10.1038/ng.3254 (2015).

\section{Acknowledgements}

This work was supported by Fondazione Cariverona Grant (Number 2017.0555). Authors acknowledge Dott. Fabio Crocetta of the Department of Ecologia Marina Integrata (EMI), Stazione Zoologica Anton Dohrn, Napoli (Italy) and Co.Ge.Vo of Ancona (Italy) and its President Domenico Lepretti for the help provided during sampling.

\section{Author contributions}

A.C., M.A.B and M.B. conceived the study, F.C. and M.A.B performed C. gallina specimens and sediment sampling, dissection, and nucleic acids extraction both for RNA and DNA next-generation sequencing. M.E.G. and S.G. performed dissection of specimens and sediment preparation for biomarkers and bioaccumulation analyses. F.C., M.A.B. and M.E.G. performed histological observations. F.C. performed gene expression analyses. E.T. performed population genetics analyses. A.Co. carried out the assessment of environmental parameters. All authors wrote the manuscript, prepared the figures, and edited the final version. All authors read and approved the manuscript.

\section{Competing interests}

The authors declare no competing interests.

\section{Additional information}

Supplementary information is available for this paper at https://doi.org/10.1038/s41598-020-75984-9.

Correspondence and requests for materials should be addressed to A.C.

Reprints and permissions information is available at www.nature.com/reprints.

Publisher's note Springer Nature remains neutral with regard to jurisdictional claims in published maps and institutional affiliations.

Open Access This article is licensed under a Creative Commons Attribution 4.0 International License, which permits use, sharing, adaptation, distribution and reproduction in any medium or format, as long as you give appropriate credit to the original author(s) and the source, provide a link to the Creative Commons licence, and indicate if changes were made. The images or other third party material in this article are included in the article's Creative Commons licence, unless indicated otherwise in a credit line to the material. If material is not included in the article's Creative Commons licence and your intended use is not permitted by statutory regulation or exceeds the permitted use, you will need to obtain permission directly from the copyright holder. To view a copy of this licence, visit http://creativecommons.org/licenses/by/4.0/.

(c) The Author(s) 2020 